\title{
Numerical analysis of the circular settling tank
}

\author{
Elahe Chero ${ }^{1}$, Mohammadamin Torabi ${ }^{2}$, Hamidreza Zahabi $^{3}$, Anahita Ghafoorisadatieh ${ }^{4}$, and \\ Keivan Bina ${ }^{5}$ \\ ${ }^{1}$ Department of Civil Engineering, Khavaran Institute of Higher Education, Mashhad, Iran \\ ${ }^{2}$ Department of Civil and Environmental Engineering, Idaho State University, Pocatello, Idaho, USA \\ ${ }^{3}$ Department of Civil Engineering, Instituto Superior Técnico, 1049-001 Lisbon, Portugal \\ ${ }^{4}$ Department of Civil Engineering, Institute of Higher Education Khazar, Mahmudabad, Iran \\ ${ }^{5}$ Department of Civil Engineering, Faculty of Engineering, Khayyam University, Mashhad, Iran
}

Correspondence: Mohammadamin Torabi (toramoha@isu.edu)

Received: 14 March 2019 - Discussion started: 17 April 2019

Revised: 5 July 2019 - Accepted: 23 July 2019 - Published: 20 August 2019

\begin{abstract}
Nowadays, a settling tank's removal efficiency is one of the most crucial matters for all water or wastewater treatment plants (WTPs or WWTPs). The unit can affect WWTP performance and improve the provided effluent quality. In this paper, the geometrical aspects of a settling tank were numerically analyzed via tracer curves, the finite-volume method, and ANSYS CFX software in which the baffle depth and diameter of a settling tank were assessed. Firstly, a previous study was similarly remodeled to verify simulation results. The impact of tank depth variation was numerically assessed where the outcomes showed that a deeper tank could raise discharge time or the hydraulic retention time (HRT). Thus, extensive discharge time may result in less polluted effluent, degrading more solids. However, the tank should not be too deeply based on costs. Moreover, the differential effect of baffle height was analyzed and indicated that lower height is more useful for boosting the HRT. An investigation of tank diameter changes also revealed that wider diameters bring about a broader HRT.
\end{abstract}

\section{Introduction}

Over the past decades, water and wastewater treatment plants (WTPs and WWTPs) have drawn government attention to water, especially environmental hazards originating from grey and sewage runoff throughout urban areas. In this regard, treatment processes can be optimally designed and operated. Therefore, one of the most critical stages in WWTPs is sedimentation in settling tanks to degrade and remove organic matters and solids. Looking at research shows that several models have simulated and analyzed the sedimentation process numerically. To simplify methods, some assumptions were effectively used to evaluate flow pattern movement as well as solids and particles in settling tanks.

According to previous studies, mathematical models are often applied instead of analytical solutions to reach precise flow characteristics (Imam et al., 1983). Moreover, three methods are suggested to have an appropriate description of flow pattern movement and characteristics (Kynch, 1952).
Firstly, the one-dimensional model is introduced in which solid vertical movement is considered (Kynch, 1952). Secondly, the two-dimensional model is presented for vertical and horizontal solid movement, which was the method once used to simplify the three-dimensional model (Imam et al., 1983). Ultimately, the three-dimensional model has more benefits thanks to orienting the flow pattern. Liu and Garcia developed a three-dimensional (3-D) numerical model to simulate large primary settling tanks in which a tracer study was used to investigate the tank's residence time (Liu and Garcia, 2010). The model was implemented on a settling tank in Chicago in the Metropolitan Water Reclamation District of Greater Chicago (MWRDGC). Throughout the case study, a computational fluid dynamics (CFD) model simulated solidremoval efficiencies. The results of the research model were used to establish the design basis for tank-side water depth, inlet feed-well dimensions, etc.; Liu and Garcia model out- 
comes can be capitalized on to decrease the cost of construction via the optimized settling tank.

Vahidfar et al. (2018) investigated and modeled a rectangular settling tank in full scale by using the CFD method to increase efficiency (Vahidfar et al., 2018). In 2018, Zahabi et al. also numerically investigated the geometry of rectangular reservoir to entrap sediments, and they found the optimum geometry (Zahabi et al., 2018).

There are a wide range of parameters which can affect settling tank performance. To illustrate this, the Reynolds number, flow viscosity, the type of hydraulic flow movement, and tank dimension and design are the most significant factors in the settling unit. Schamber and Larock once used the $k-\varepsilon$ turbulence model to simulate the settling stage applying for a high Reynolds number and turbulent flow (Schamber and Larock, 1983). According to the study, coarse solids with a high specific weight increase the Reynolds number; therefore, this type of model is typically conducted for a settling unit. Furthermore, a study showed that the $k-\varepsilon$ turbulence model agreed well with some experiments in a simple geometric tank (Adams and Rodi, 1990). The quality of the computations, however, deteriorates with increasing flow complexity. In fact, the effects of flow curvature are mainly applied to clarify the differences between computation and experiment, which are not a part of the standard $k-\varepsilon$ model. Also, a mathematical model was used to predict the velocity and particle transport pattern in secondary rectangular tanks. The particle impacts in terms of bottom current, surface return flow, and the solid concentration distribution of density stratification on the hydrodynamics were analyzed by Zhou and McCorquodale (1992). Consequently, the model was used to simulate the so-called density waterfall phenomenon in the front end of a settling tank.

It is suggested that effluent concentration changes through velocities in the withdrawal zone (McCorquodale and Zhou, 1993). It is also shown that there is more upward velocity in the withdrawal zone by decreasing the densimetric Froude number for a constant discharge, showing the relationship between the densimetric Froude number and hydraulic and solid loads. The density of the waterfall can capture large volumes of the ambient fluid in the physical and numerical models (Zhou and McCorquodale, 1992). Also, the entrainmentcompensating flow rate is indirectly related to the densimetric Froude number. Furthermore, the bottom strength of the current density, the upward flow in the withdrawal zone, and the recirculation all increase as the densimetric Froude number decreases due to entrainment into the density waterfall.

Some research also addressed an array of CFD modeling in the wastewater treatment (WWT) field (Dutta et al., 2014; Daneshfaraz et al., 2016; Zhang et al., 2016). For instance, Wicklein et al. proposed a good modeling practice (GMP) for wastewater application, and it is based on general CFD procedures (Wicklein et al., 2016; Daneshfaraz et al., 2017).

Settling basins can be divided into two categories in terms of geometry, which are cubic and cylindrical in shape. In this
Table 1. Properties of settling tank.

\begin{tabular}{llr}
\hline Parameters & Unit & Dimension \\
\hline Tank diameter & $(\mathrm{m})$ & 47.24 \\
Baffle diameter & $(\mathrm{m})$ & 12.8 \\
Tank depth & $(\mathrm{m})$ & 3.66 \\
Baffle height & $(\mathrm{m})$ & 1.52 \\
Inlet pipe diameter & $(\mathrm{m})$ & 1.37 \\
Bottom slope & - & $1 / 12$ \\
\hline
\end{tabular}

Table 2. Tracer curve outcome for the two aforementioned studies.

\begin{tabular}{lrrr}
\hline $\begin{array}{l}\text { Time of discharge } \\
\text { (h) }\end{array}$ & $\begin{array}{r}\text { Time of discharge } \\
(\mathrm{h})\end{array}$ & $\begin{array}{r}\text { Baffle } \\
\text { height } \\
(\mathrm{m})\end{array}$ & $\begin{array}{r}\text { Tank } \\
\text { depth } \\
(\mathrm{m})\end{array}$ \\
\hline 1.22 & 1.19 & 1.52 & 3.66 \\
1.25 & 1.14 & 2.13 & 3.66 \\
\hline
\end{tabular}

regard, circular basins are better than rectangular ones, since they need less area for construction. This might increase rectangular basin hydraulic efficiency (Stamou et al., 1989). In this study, some circular basins are considered to be a threedimensional model to simulate tank geometry and stream direction. Meanwhile, continuity and momentum equations will be analyzed via the finite-volume method, and the density change of the particles is ignored. Eventually, the tracer curve will be used to evaluate hydraulic efficiency in terms of basin depth, and also the tank diameter variation will be studied to assess repercussions.

\section{Material and methods}

An increase in settling time results in tank sedimentation efficiency; considering the appropriate size for a tank's baffle and the weir structure are two ways to improve tank efficiency. In this light, baffles may cause returning flow when flow reaches the baffle and weir structure, extending the distance that flow travels to discharge from the basin tank. In this paper, the aim is to study and evaluate the Chicago basin tank which was evaluated in 2011 to analyze the basin's depth and diameter changes and its effects on effluent quality (Liu and García, 2010). In this respect, tank properties are presented in Table 1.

The Chicago tank is capable of maintaining flow being treated into the basin by increasing retention time, which happens while a weir is considered with a shorter height, causing a longer distance for the flow to exist. Therefore, the mechanism triggers to provide more time for settling. On the other hand, the flow turns when it reaches the baffle wall. In this regard, the process is evaluated via the ICEM CFD model. The mesh in the model is 12 million rectangular meshes (Tetra Unstructured Tetrahedral Grid), where the larger and shorter bases are 10 and $2 \mathrm{~cm}$, respectively. The 


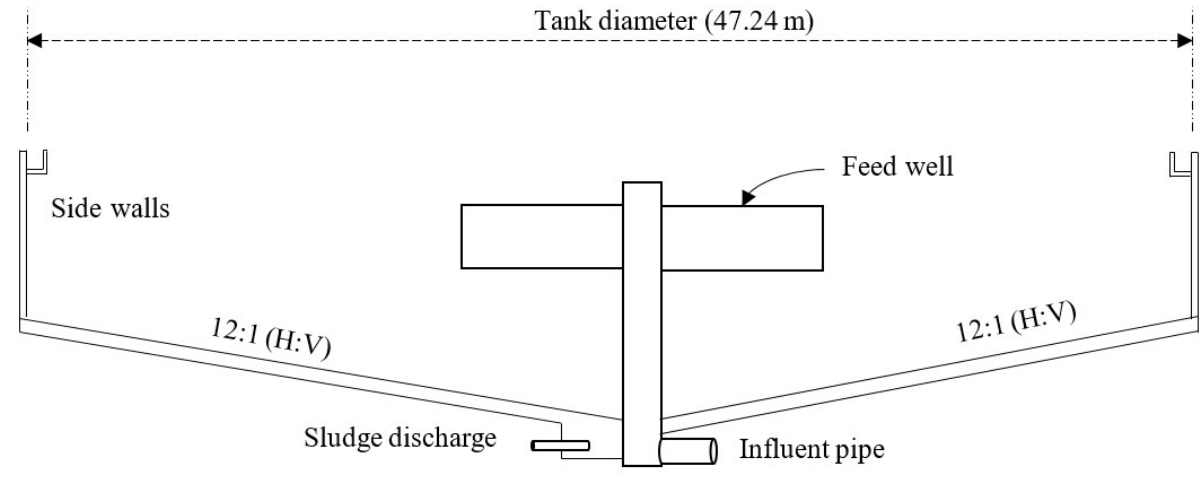

Figure 1. Schematic view of Chicago tank - adapted from Liu and Garcia (2010).
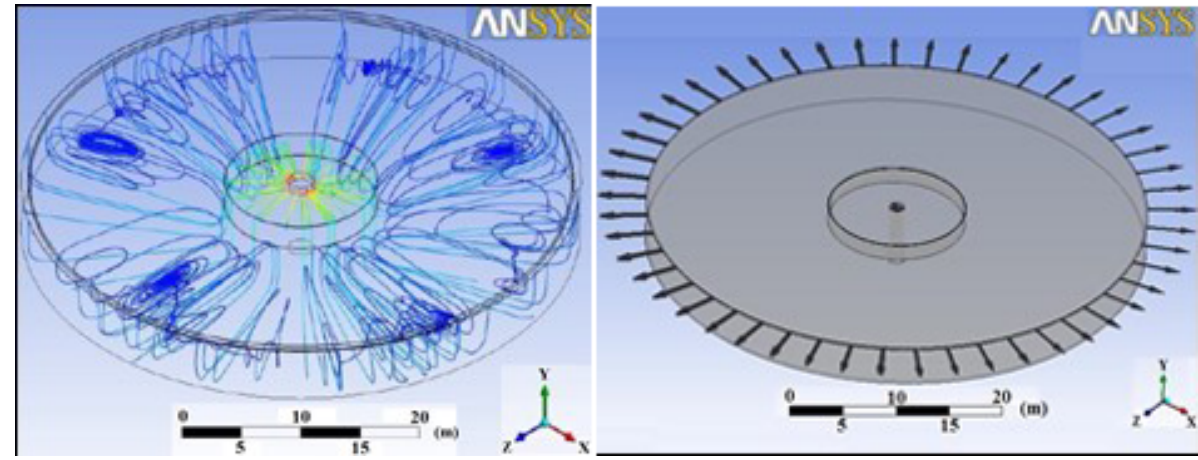

Figure 2. Flow lines and directions in the settling tank.

tank which was studied by Garcia and flow lines along with the tank mesh system are shown in Figs. 1, 2, 3, and 4. It should be added that geometrical modeling was done by ANSYS CFX software in the current study. The $k-\varepsilon$ turbulent model was also used for simulation.

To simplify the model and obtain an accurate result, some assumptions are considered, including that of the flow pattern being steady. Temperature variation is ignored, and flow temperature, density, and velocity are assumed to be constant $\left(T=20^{\circ} \mathrm{C}\right.$; flow density $\left.=998 \mathrm{~kg} \mathrm{~m}^{-3}\right)$. In addition, boundary conditions are conducted in three main steps in which the tank's surface is taken to be a slippery surface except for the bottom of the tank. The free surface is rigid, and the flow pressure is calculated hydrostatically. Relative pressure at the end is zero, and the inlet is velocity radial control.

One way to calculate the settling tank's efficiency is to draw a tracer curve. The method is defined as a way in which the pigment flow is carried out to the influent, and then, when the pigment reaches the effluent, the pigment concentration is measured. Following this, three steps are taken to draw the racer curve comprised of solving the flow equation steadily in ANSYS solver, defining the pigment in the pre-CFX ANSYS, and then checking pigment concentrations in the influent and effluent after $3 \mathrm{~h}$. It should be added that hydrodynamic conditions are expressed in terms of three laws in which the conservation of mass, the conservation of momentum (Newton's second law), and the conservation of energy (the first law of thermodynamics) are considered.

\section{Tracer curve method evaluation}

The maximum time of the flow discharge in the current study will be compared with Garcia outcomes in a similar way in order to make an evaluation (Garcia, 2011). Figure 4 shows the comparison between these two studies in the sense of tracer curves. Table 1 also shows the maximum time of the tracer curves when tank depths are taken at a $12 \mathrm{ft}$ depth and at two different baffle heights of 2.13 and $1.52 \mathrm{~m}$ to compare with Garcia's results.

As observed, data dispersion (the current study) is in good agreement with the Garcia study in which trend lines are going up by a $45^{\circ}$ slope. Beside this, the standard deviations of graphs in both Fig. $4 \mathrm{a}$ and $\mathrm{b}$ are close to 1 . Therefore, modeling of the Chicago tank by a tracer curve is effective and accurate enough to predict other basin tank depths and baffle heights. 

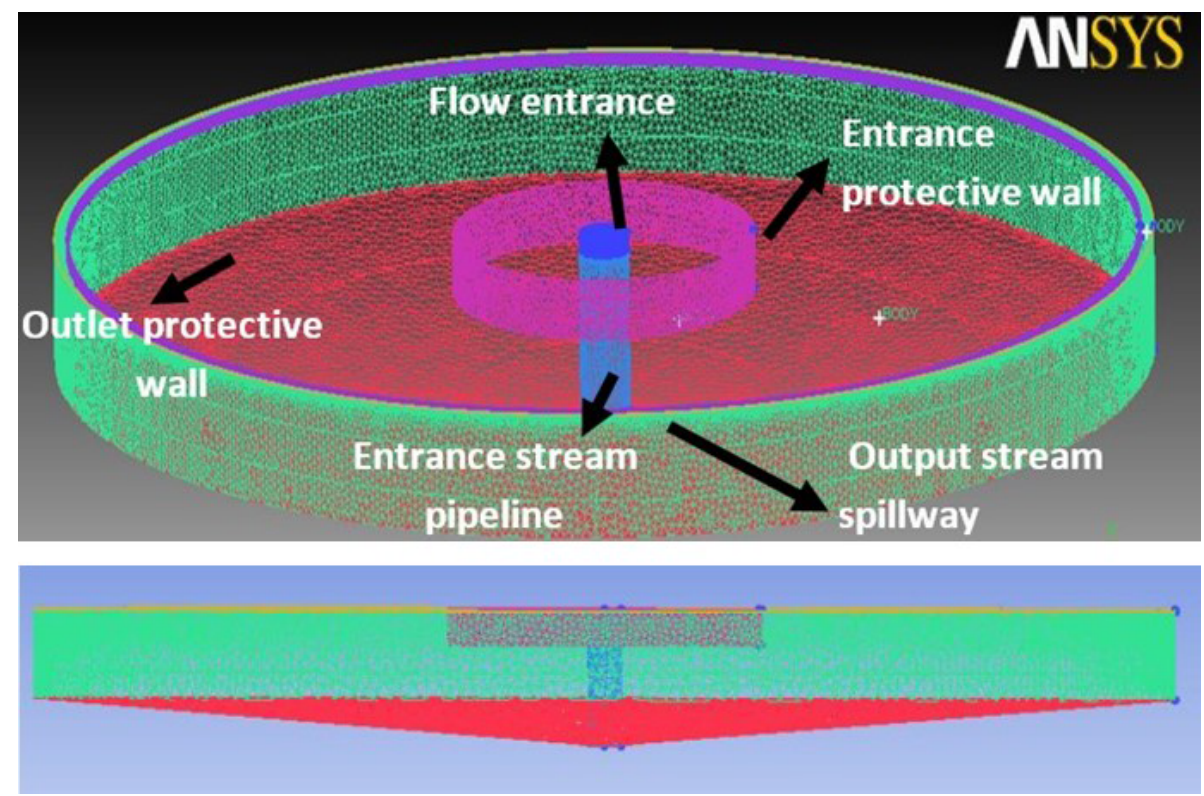

Figure 3. Modeled settling tank.

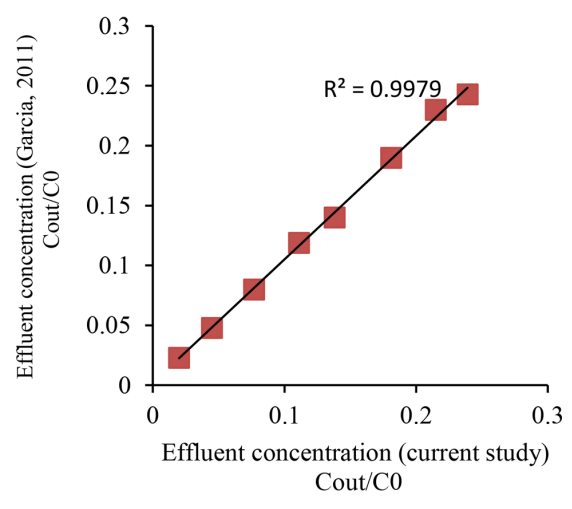

(a) Baffle height of $5 \mathrm{~m}$

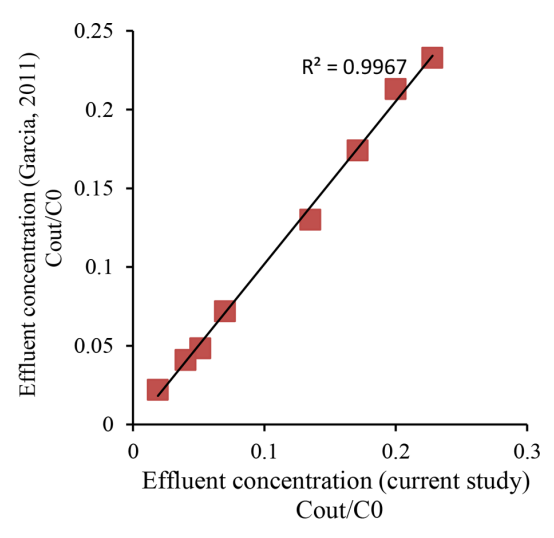

(b) Baffle height of $7 \mathrm{~m}$

Figure 4. Data dispersion in current and Garcia studies (2011).

\section{Result and discussion}

\subsection{The effect of tank depth variation}

The tracer curves evaluate the tank performance where the tank depth $\left(D_{\mathrm{t}}\right)$ and the baffle height $\left(D_{\mathrm{f}}\right)$ change with a $5 \mathrm{~s}$ pigment injection. Then, the pigment concentrations will be measured in the inlet and outlet (effluent) over $3 \mathrm{~h}$ to find the difference. Figures 5 and 6 display the tracer curve results for a tank depth variation and baffle height of 1.52 and $2.13 \mathrm{~m}$, in which the tank diameter is equal to $47.24 \mathrm{~m}$.

According to Fig. 5, as tank depth increases, it takes more time $\left(t_{\max }\right)$ to discharge effluent. Therefore, the hydraulic retention time (HRT) will rise slightly, which is more evident in peak point locations. It is clear from the data given that a $0.34 \mathrm{~h}$ time elapse is observed from the $3.66(1.19 \mathrm{~h})$

to $1.52 \mathrm{~m}(1.53 \mathrm{~h})$ depth peak point distance. Moreover, the greater the tank depth, the thinner the gaps between peak points become. Particularly, the gap between 4.57 and $1.22 \mathrm{~m}$ tank depths is narrower compared with the gap between 3.66 and $3.96 \mathrm{~m}$ or even the gap between tank depths of 3.96 and $4.27 \mathrm{~m}$. If the tank depth is more than $4.57 \mathrm{~m}$, the gap will not be noticed. Thus, tank depths which are more than $4.57 \mathrm{~m}$ are not economically beneficial because there would not be excessive time discharge for the tank. This means that building larger tanks is not cost-efficient because it does not have a positive impact on effluent concentration.

Furthermore, the points $\left(t_{0}\right)$ where the lines start to have more effluent concentration and the tank is being filled with pollution are different. To illustrate that, the starting points are 0.64 and $0.91 \mathrm{~h}$, respectively, for tank depths of 3.66 and $4.57 \mathrm{~m}$. Therefore, deeper tanks become polluted later. Com- 


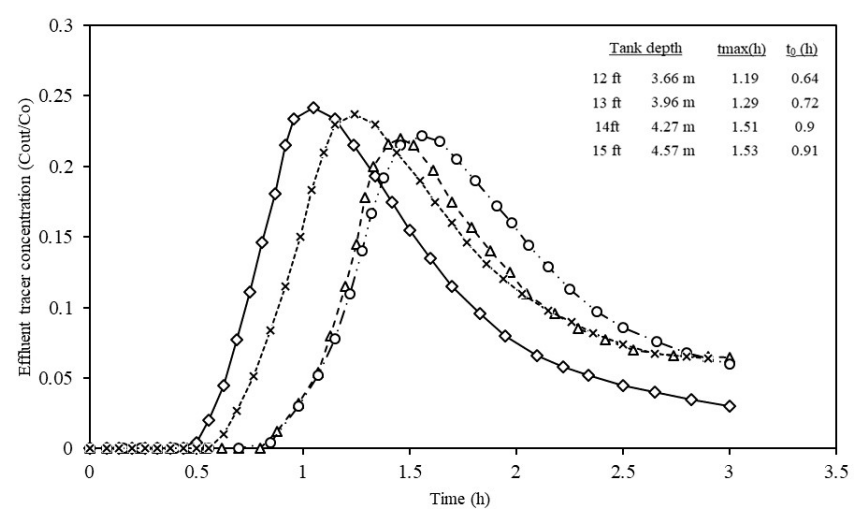

Figure 5. Effluent concentration with a baffle height of $1.52 \mathrm{~m}$ in tank depth variations.

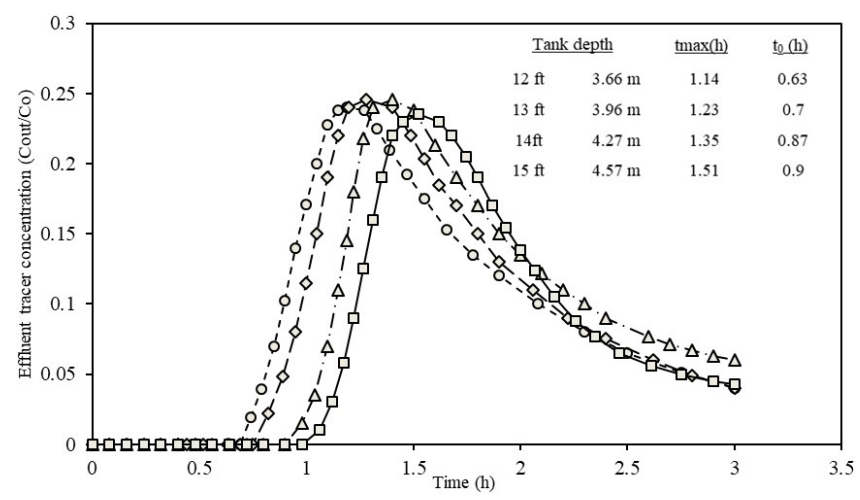

Figure 6. Effluent concentration with a baffle height of $2.13 \mathrm{~m}$ in tank depth variations.

paring the maximum points' effluent concentration indicates that the $C_{\text {out }} / C_{\mathrm{o}}$ ratio falls markedly from 3.66 to $4.57 \mathrm{~m}$ tank depths given that the optimum tank depth is $4.57 \mathrm{~m}$; however, there is not a significant gap between 4.27 and $4.57 \mathrm{~m}$ depths.

Figure 6 (baffle height of $2.13 \mathrm{~m}$ ) also shows a similar behavior to that seen in Fig. 5. However, $t_{\max }$ is slightly less than that in Fig. 5. Plus, the effluent concentrations $\left(C_{\text {out }} / C_{\mathrm{o}}\right.$ ratio) are almost equal for all tank depths, with a small drop from tank depths of 3.66 to $4.57 \mathrm{~m}$. Also, the same behavior holds for $t_{0}$, as discussed previously.

Overall, there is no significant difference between a tank baffle of 1.52 and $2.13 \mathrm{~m}$. However, a tank baffle of $5 \mathrm{~m}$ can provide more HRT or discharge time by tracer curve calculations with the same properties.

\subsection{The effect of tank diameter variation}

Tank diameter can change $t_{\max }$, and following that, effluent concentration may vary. The effect of diameter variation on these parameters is analyzed in this part. A tank baffle of $1.52 \mathrm{~m}$ generates less effluent concentration. It is selected for the following comparison. Figures 7 and 8 display tank performances for tanks that are 42.67 and $51.8 \mathrm{~m}$ in diameter

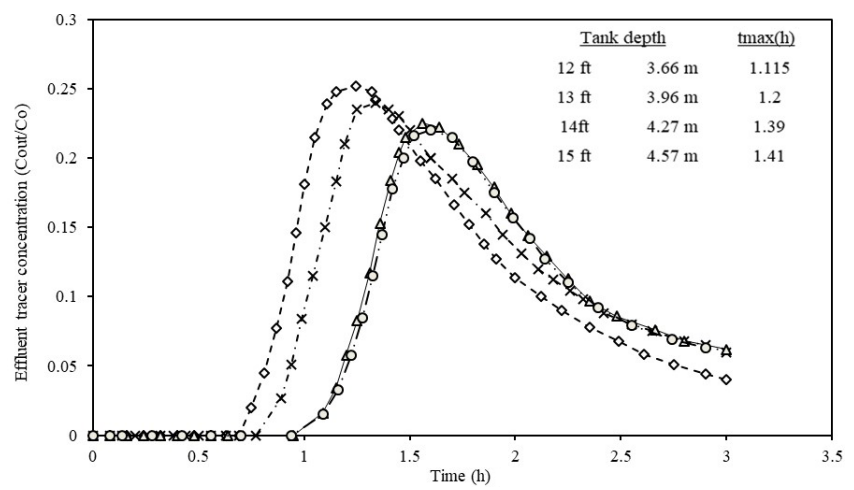

Figure 7. Effluent concentration and $t_{\max }$ in tank depth variations and $42.67 \mathrm{~m}$ diameter.

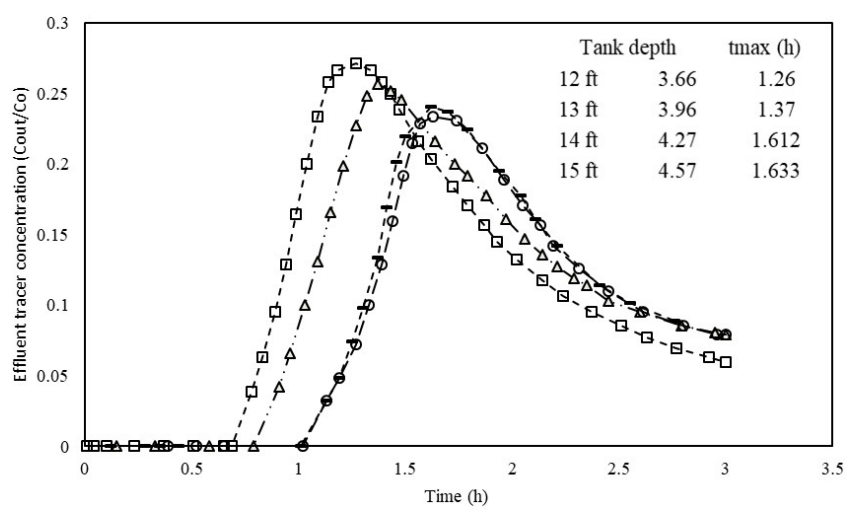

Figure 8. Effluent concentration and $t_{\max }$ in tank depth variations and $51.82 \mathrm{~m}$ diameter.

and for which tank depths are 3.66, 3.96, 4.27, and $4.57 \mathrm{~m}$, respectively.

Figures 7 and 8 show that $t_{\max }$ changes considerably when the diameter increases from 42.67 to $51.82 \mathrm{~m}$. $t_{\max }$ rises noticeably. This is even more evident for a tank depth of $4.57 \mathrm{~m}$ in two figures in which $t_{\max }$ is 1.41 and $1.63 \mathrm{~h}$ for 42.67 and $51.82 \mathrm{~m}$ diameters, respectively. In addition, there are still gaps among lines which become narrower as tank depth increases.

\section{Conclusions}

In this study, a tracer curve is used to analyze settling tank performance in which the given tank is firstly evaluated with the previous study. The results of the evaluation were homogenized with the study, and similar outcomes were generated. Then, the effects of tank depth variation, baffle height, and tank diameter were investigated. It was determined that a greater tank depth increases the discharge time. Also, when the tank depth is higher, the effluent concentration is lower. Comparing baffle heights of 1.52 and $2.13 \mathrm{~m}$ showed that the discharge time is wider with a baffle height of $1.52 \mathrm{~m}$. Therefore, smaller baffle heights are effective in delaying the ef- 
fluent discharge time. Tank diameter variation analysis indicated that a larger tank diameter results in a greater discharge time, which is evident for a tank depth of $51.82 \mathrm{~m}$ compared with $45.72 \mathrm{~m}$. The time in which a tank gets polluted and the effluent becomes concentrated also depends on tank depth and diameter. For larger tanks the time increases when the tank depth and diameter are considered for larger sizes.

Data availability. The datasets generated and/or analyzed during the current study are available from the authors upon reasonable request.

Author contributions. EC did the numerical work and was the principal investigator. MT supervised the whole work and numerical modeling. $\mathrm{HZ}$ and $\mathrm{AG}$ contributed to writing the paper. $\mathrm{KB}$ was the investigator and contributed to writing the paper.

Competing interests. The authors declare that they have no conflict of interest.

Acknowledgements. We thank the ASCE permission office and (Liu and Garcia, 2010) for their interesting paper. Figure 1 is redrawn but adapted from Liu and Garcia (2010).

Review statement. This paper was edited by Mirjam Blokker and reviewed by five anonymous referees.

\section{References}

Adams, E. W. and Rodi, W.: Modeling flow and mixing in sedimentation tanks, J. Hydraul. Eng., 116, 895-913, https://doi.org/10.1061/(ASCE)0733-9429(1990)116:7(895), 1990.

Daneshfaraz, R. and Ghaderi, A.: Numerical investigation of inverse curvature ogee spillway, Civ. Eng. J., 3, 1146-1156, https://doi.org/10.28991/cej-030944, 2017.

Daneshfaraz, R., Joudi, A. R., Ghahramanzadeh, A., and Ghaderi, A.: Investigation of flow pressure distribution over a stepped spillway, Advances and Applications in Fluid Mechanics, 19, 805-822, 2016.
Dutta, S., Tokyay, T. E., Cataño-Lopera, Y. A., Serafino, S., and Garcia, M. H.: Application of computational fluid dynamic modelling to improve flow and grit transport in Terrence J. O'Brien Water Reclamation Plant, Chicago, Illinois, J. Hydraul. Res., 52, 759-774, https://doi.org/10.1080/00221686.2014.949883, 2014.

Imam, E., McCorquodale, J. A., and Bewtra, J. K.: Numerical modeling of sedimentation tanks, J. Hydraul. Eng., 109, 1740-1754, https://doi.org/10.1061/(ASCE)0733-9429(1983)109:12(1740), 1983.

Kynch, G. J.: A theory of sedimentation, T. Faraday Soc., 48, 166176, https://doi.org/10.1039/TF9524800166, 1952.

Liu, X. and García, M. H.: Computational fluid dynamics modeling for the design of large primary settling tanks, J. Hydraul. Eng., 137, 343-355, https://doi.org/10.1061/(ASCE)HY.19437900.0000313, 2010.

McCorquodale, J. A. and Zhou, S.: Effects of hydraulic and solids loading on clarifier performance, J. Hydraul. Res., 31, 461-478, https://doi.org/10.1080/00221689309498870, 1993.

Schamber, D. R. and Larock, B. E.: Particle concentration predictions in settling basins, J. Environ. Eng., 109, 753-764, https://doi.org/10.1061/(ASCE)0733-9372(1983)109:3(753), 1983.

Stamou, A. I., Adams, E. W., and Rodi, W.: Numerical modeling of flow and settling in primary rectangular clarifiers, J. Hydraul Res., 27, 665-682, https://doi.org/10.1080/00221688909499117, 1989.

Vahidifar, S., Saffarian, M. R., and Hajidavalloo, E.: Introducing the theory of successful settling in order to evaluate and optimize the sedimentation tanks, Meccanica, 53, 3477-3493, https://doi.org/10.1007/s11012-018-0907-2, 2018.

Wicklein, E., Batstone, D. J., Ducoste, J., Laurent, J., Griborio, A., Wicks, J., and Nopens, I.: Good modelling practice in applying computational fluid dynamics for WWTP modelling, Water Sci. Technol., 73, 969-982, https://doi.org/10.2166/wst.2015.565, 2016.

Zahabi, H., Torabi, M., Alamatian, E., Bahiraei, M., and Goodarzi, M.: Effects of Geometry and Hydraulic Characteristics of Shallow Reservoirs on Sediment Entrapment, Water, 10, 1725, https://doi.org/10.3390/w10121725, 2018.

Zhang, J., Liu, X. I., Tejada-Matinez, A., and Zhang, Q. I.: Computational Fluid Dynamics: A promising Tool for Analysis and Design of Water and Waste-water treatment, Hydrolink, Hidraulics of Wastewater Treatment, 2, 2016.

Zhou, S. and McCorquodale, J. A.: Modeling of rectangular settling tanks, J. Hydraul. Eng., 118, 1391-1405, https://doi.org/10.1061/(ASCE)0733-9429(1992)118:10(1391), 1992. 